\section{Failure Analysis of Superheater Tubes Made from Material T91 in the Boiler of a 600 MW Power Plant}

\author{
Khabib Abdul Muniff \\ Department of Mechanical Engineering, Institut Teknologi Sepuluh Nopember, Surabaya 60111, Indonesia \\ Received: 2 January 2020, Revised: 1 March 2020, Accepted: 5 March 2020
}

\begin{abstract}
This paper highlights a study for the failure investigation of superheater tubes made of the material T-91 of a boiler in the coal-fired power plant. Two tubes are subjected to different types of failure. Visual examination, dimensional measurement, and chemical analysis are conducted as part of the study. Apart from these, the hardness test and microstructural analysis are also conducted to ascertain the possible cause of failure. The superheater tube material cracking, cavity until broken failure that occurred on the first tube was resulted in thick lip rupture and the second tube resulted in thin lip fish mouth rupture. Creep deformation, localized rapid overheating, surface tube erosion, and fly ash of coal corrosion are the main cause of tube failure. It can be avoided by regularly and according to standards cleaning the scale or deposit on the surface of the tube.
\end{abstract}

Keywords: Boiler, failure, superheater, thick lip rupture, thin lip fish mouth rupture

\section{Introduction}

Fossil-fuel power plants are still the main electricity supplier in Indonesia, with coal being the fuel of the power plant most widely used by power plants in Indonesia. One important component in the coal power plant is the boiler. The function of the boiler is to produce the superheated steam which is fed on a steam turbine. The boiler consists of different critical components like economizer, water wall, superheater and reheater [1]. The main advantage of using superheater tubes is to reduce fuel consumption [2].

Failure of the superheater can lead to a forced outage of the boiler work, resulting in huge losses. Some of the causes of failure in superheaters are localized prolonged heating, creep damage, thermal fatigue, excessive thermal stresses, water and fireside corrosion, erosion. General modes of failures observed in superheaters are wall thinning, reduced thickness, fish-mouth opening type bursting, creep cracks on tube surfaces and puncturing [3]. Approximately $35 \%$ of common failures in utility boilers are caused by long term overheating (creep) in superheaters, reheaters and wall tubes [4].

Based on literature study, was many reported tubes failure in a superheater. Movahedi et al. [2] investigated the failure analysis of the ASTM A213 Grade-TP347H superheater tube in an oil-fueled boiler power plant. Its found the fireside corrosion of the tube which already served for 20 year until the damage occurred. The low grade of used fuel, sodium, sulfur and vanadium element were observed and causing reduction of wall tube thickness. Husain and Habib [5] investigated the failure of the tube in a superheater boiler at Power plants which suffered localized overheating. Haghighat-Shishavan et al. [6] investigated the failure of a high-temperature superheater tube of a fossil fuel power plant boiler. The tube was made of low-alloying steel, ASTM A 213-T12. The creep failure of tube mostly occurring under different temperature and time conditions are deduced from the morphology of fracture and the change in microstructure. Methods for analyzing tube failures are performed in order of a. visual inspection, b. microscopic observation, c. estimation of creep mechanism, and d. corrosion products analysis. Gupta and Chattopadhyaya [3] studied a generalized methodology for the investigation of failed superheater tubes by considering feasible influential factors with suggestions for remedial actions. The tube made of the material T-22 failures that were observed ie. significant wall thinning, layer-wise oxidation corrosion (exfoliation), straight-line crackings and creep deformation under service exploitation. The failure mechanism was identified to be a result of excessive oxidation corrosion. Baoyou et al. [7] analyzed a boiler tube rupture through chemical analysis, scanning electron microscope, and energy dispersion spectroscopy. Within 5 months usage of the tube was burst. It is because the high-temperature strength of the material was below the designed standard. Rahman et al. [8] presented a failure investigation on a division wall superheater tube of Boiler Unit 4 at Sultan Shalahuddin Abdul Aziz Shah Power Station by visual inspections, metallurgical examination, and temperature estimation using the empirical formula. The failed SA213-T 22 tube was caused by localized overheating due to the formation

*Corresponding author. Email : abibmunif@gmail.com 
of clinker because of the burning of low-quality coal. In addition, the molten ash had worsened the situation by synergically causing coal-ash corrosion.

In this paper, failure analysis of the superheater tube is comprehensively investigated with guidance of previous research and literature study. The research is based on events of tube failure that occurred twice in 2017-2018. Plant downtime more than 2 weeks for recovery. The location of both failures in the boiler is shown in Figure 1. Two tubes failures in secondary superheater outlet at boiler 600 MW coal power plant. The tubes are made of alloy steel SA 213 T91 with the intended operating temperature of $540^{\circ} \mathrm{C}$, which was applied continuously and the average steam pressure is $174 \mathrm{~kg} / \mathrm{cm}^{2}$. The outer diameter (OD) of the tube was $50.8 \mathrm{~mm}$ and thickness $9.1 \mathrm{~mm}$. The code of failure tubes is 6 and 7 with the location of failure respectively in the bank 11 row 8 and bank 11 row 11 of the secondary superheater outlet bundle.

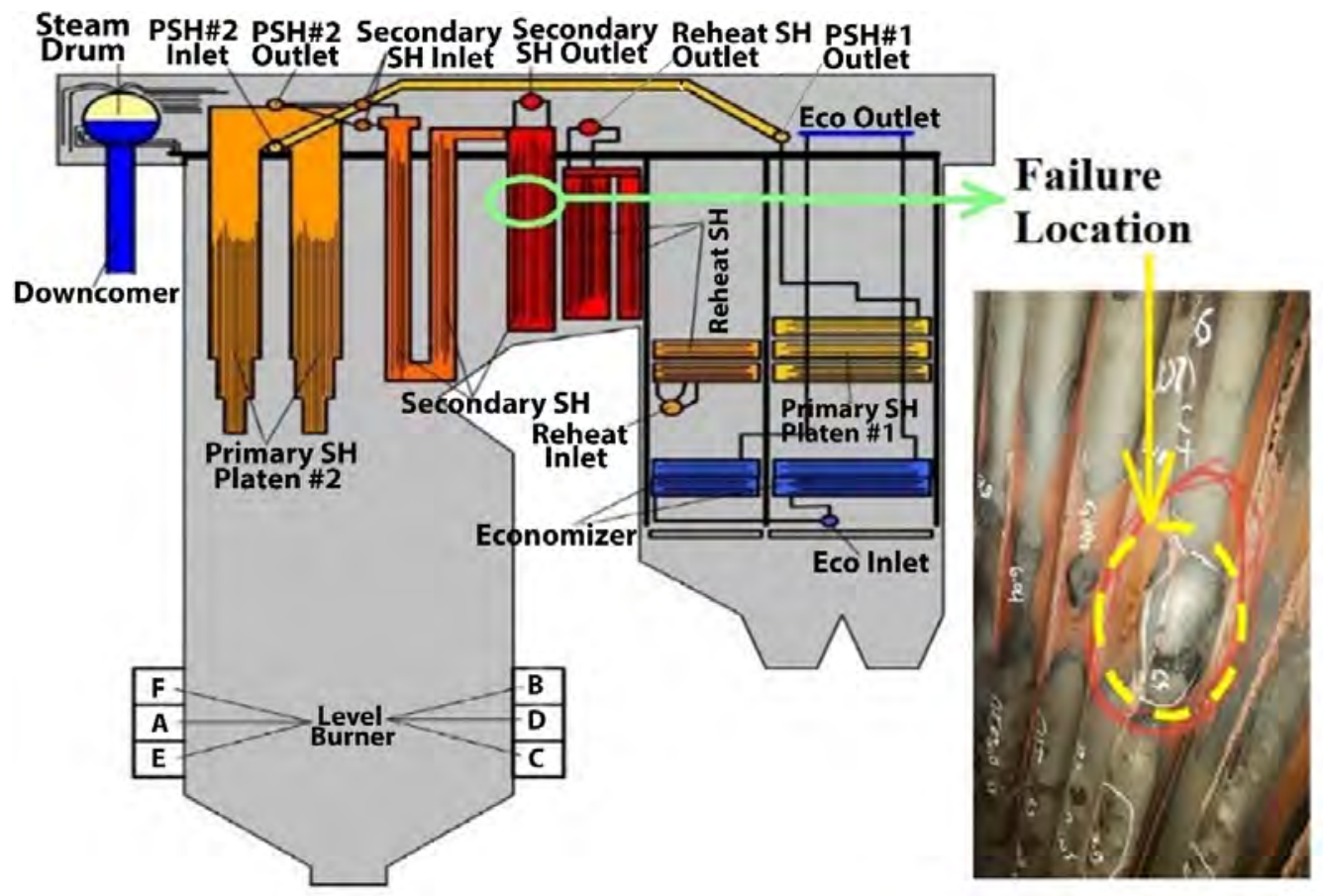

Figure 1. The location of failure tubes

\section{Experimental method}

This research begins with a visual inspection and wall thickness measurements. Direct observation by visual is performed to see the pattern and shape of damage and find the point of damage based on location in the field. Wall thickness measurements were done to assess the impact of the operational situation on the tube wall thickness. Documentation should be in a proper manner.

This research begins with a visual inspection and wall thickness measurements. Direct observation by visual is performed to see the pattern and shape of damage and find the point of damage based on location in the field. Wall thickness measurements were done to assess the impact of the operational situation on the tube wall thickness. Documentation should be in a proper manner.

Followed by hardness test to determine the hardness of tube material using Zwick Vickers Hardness Tester used with and a load of 500 grams and dwelling time 15 seconds. Microstructure analysis is carried out on the tube material to determine the changes in microstructure that may occur to provide an overview of the failure mechanism experienced by the tube. This method using optical microscopy and Scanning Electron Microscope and Energy Dispersive X-ray Spectroscopy (SEM-EDS) to determine failure mechanism microstructure analysis. Observation of microstructure by using SEM-EDS aims to look deeper into the microstructure that occurs that cannot be accommodated by optical microscopy due to limited magnification. Also, by using Energy Dispersive X-ray Spectroscopy (EDS) that is integrated into SEM, it aims to find out the elements that exist in the local area being examined.

\section{Investigation Results}

\subsection{Visual Inspection}

Visual inspection of the material is the first step used to identify the initial failure of the material. Visual examination is conducted on the failed superheater tube. In tube code 6 , where the thick lip fish mouth failure type occurs, and the tube is exposed exceeding the operating temperature limit for a long time, it is ensured that creep 
is the only mechanism causing the damage. This is showed by the tube walls are not experiencing thinning or plastic deformation, and there is no material flow. Overheating occurs in the tube caused by a deposit slagging thick on the outer wall of the tube so that there is uneven heat distribution on the tube . Visual inspection of tube code 6 is shown in Figure 2, and tube code 7 is shown in Figure 3 The opening burst tube of the tube with code 6 has a size of about $8.5 \mathrm{~cm}$ and a width of $5 \mathrm{~cm}$, it is shown by Figure $2 \mathrm{a}$. The damage type of this tube is a thin-lipped rupture with narrow open bursts that crack in the longitudinal direction and occur site (swelling), it is shown in Figure $2 \mathrm{~b}$ The tube walls have experienced relatively even thinning. Wall thickness of the rupture lips/edges are between $1.37-$ $3.13 \mathrm{~mm}$, shown in Figure 2c. Dimensional measurement

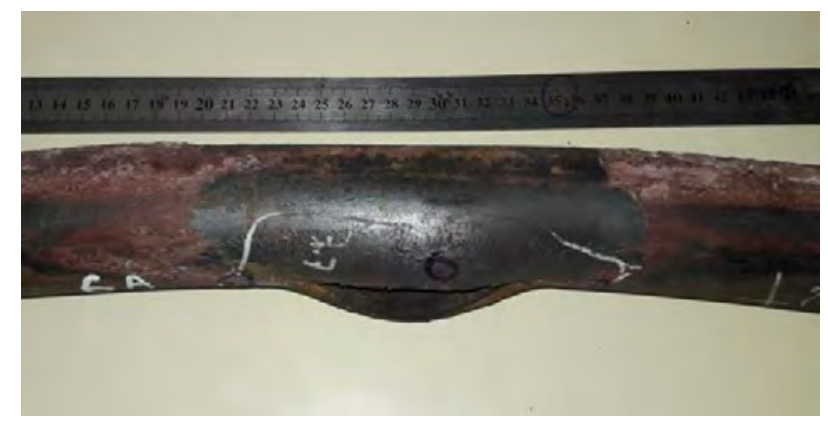

(a) The dimension of failure

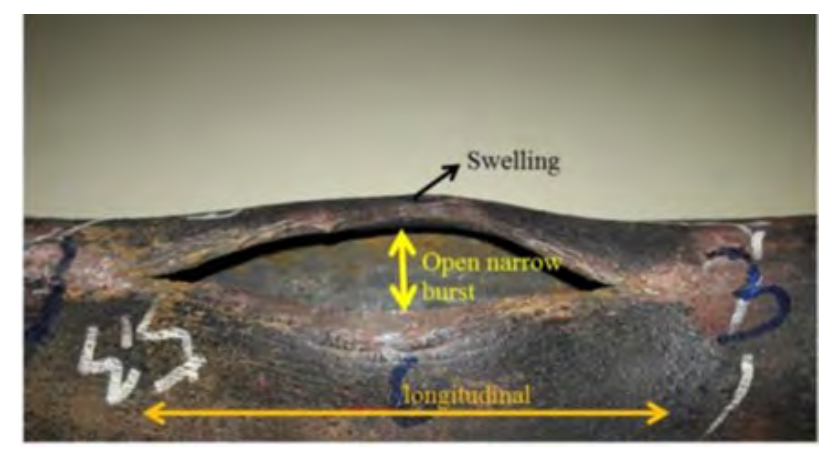

(b) The failure characteristics

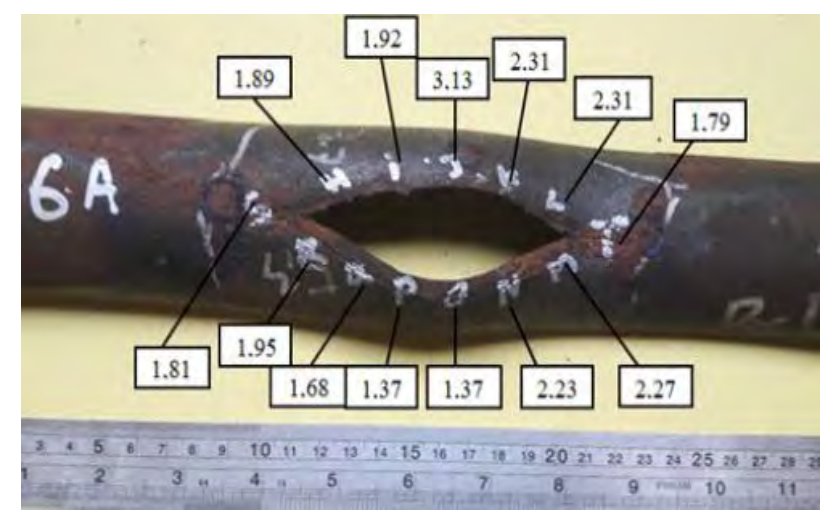

(c) The tube thickness of the rupture area in $\mathrm{mm}$

Figure 2. Visual inspection of tube code 6 results showed that the tube diameter increased by about $10 \%$, as evidenced by the inflation of the tube. There is no localized thinning on the surrounding area of rupture.

The opening burst tube size of the tube with code 7 has a size of about $3.5 \mathrm{~cm}$ in length and $7 \mathrm{~cm}$ wide, shown in Figure 3a. Thin lip-type tube damage where thinning occurs starting from the outer wall of the tube and the presence of an oxide layer indicating the mechanism of damage that occurs is erosion and corrosion. The tube has the failure of thin lip fish mouth rupture type and a wide opening (fish mouth) burst, shown in Figure 3b. It is shown from the thickness measurement where localized thinning occurs in the rupture area. Wall thickness of the rupture lips/edges is between $0.90-2.89 \mathrm{~mm}$. It is shown in Figure $3 \mathrm{c}$.

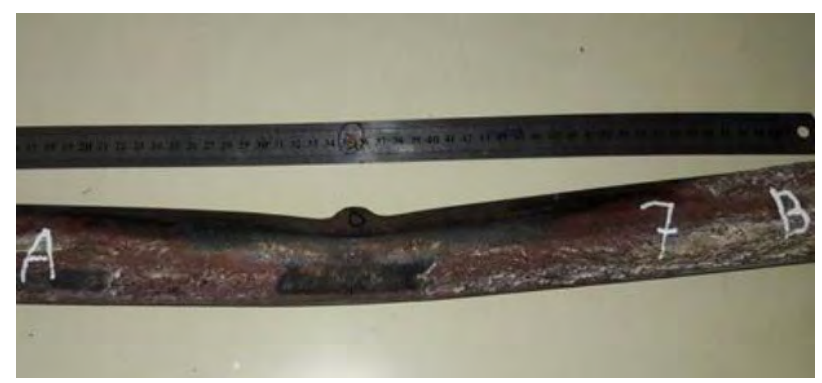

(a) The failure tube with tube code 7

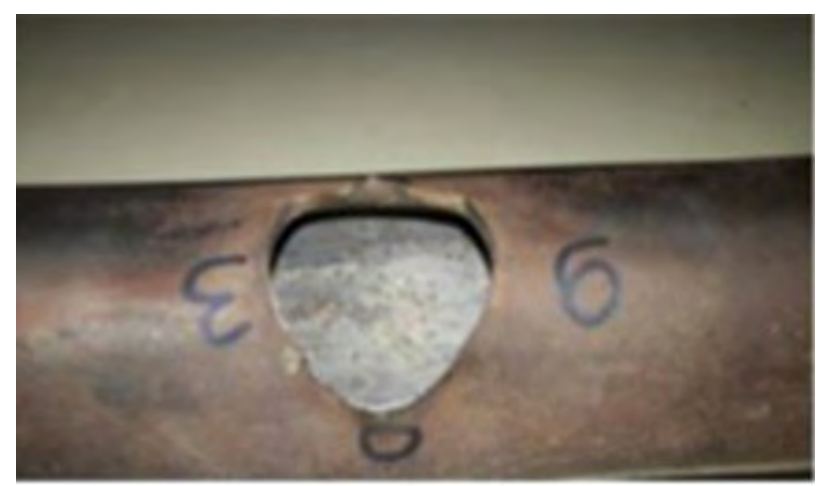

(b) The oxide layer failure characteristics tube with tube code 7

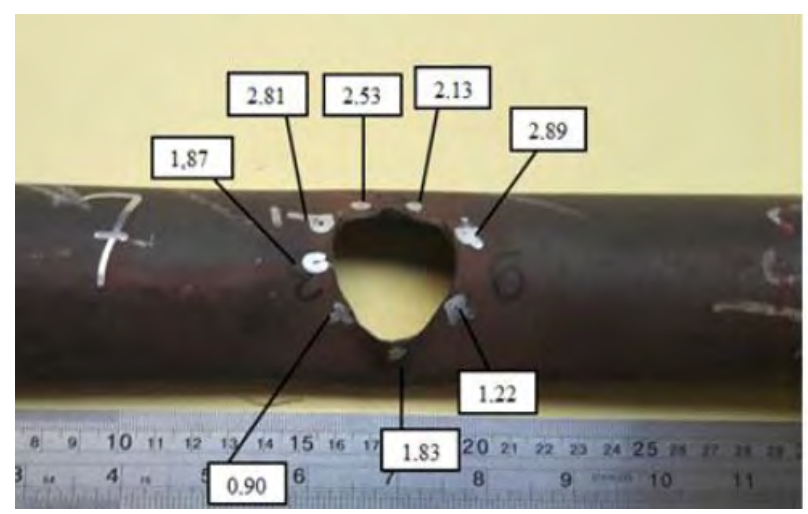

(c) The tube thickness of the rupture area in $\mathrm{mm}$

Figure 3. Visual inspection of tube code 7 


\subsection{Testing of chemical composition}

A chemical analysis was performed on the materials of the tube to determine the chemical composition. The results of the chemical composition test show no deviation of chemical composition that can provide on the tube failure. The materials composition of the tube is as shown in Table 1 .

\subsection{Hardness Test}

The hardness test is one way to find out the strength or resistance of a material (material). Hardness is one of the mechanical properties of a material, in addition to its physical and technological properties. Sample location for hardness test tube with code 6 taken from the part as shown in Figure 4. The hardness readings are then used for estimating the operating metal temperature at the time of failure, considering that the operating service is 38 hours.

Correlation between hardness (HV) and the LarsenMiller parameter for SA213 T91 (9Cr-1Mo-1V steel) may be expressed as [9]:

$$
\text { Hardness }(H V)=933-0.1825 P
$$

where $\mathrm{P}$ is the Larsen-Miller parameter and defined as:

$$
P=\left(\frac{9}{5} T_{c}+492\right)(C+\log (t))
$$

where $\mathrm{T}_{c}$ is the temperature in degrees Celsius, $\mathrm{t}$ is the rupture time in hours, and $\mathrm{C}$ is a constant equal to 20 .

Equations 1 and 2 are used for estimating the operating metal temperatures of the as-received tubes based on the hardness readings, and the estimations are tabulated in Table 2. It can be seen from Table 2, the estimated metal temperatures indicated that the tubes had experienced higher-temperature operation above $800^{\circ} \mathrm{C}$.

Sample location for hardness test tube with code 7 taken from the part as shown in Figure 5. The hardness on the tube with code 7 is shown in Table 3. This shows the variation in the level of hardness on the rupture lip area, and that is away from the rupture lip. There is a significant difference in the hardness value which indicates that there has been a change in the microstructure and there is also localized overheating in the area of the damaged lip. This can be seen from Table 3 , in which the estimated metal temperatures indicated that the tubes had experienced higher-temperature operation above $800^{\circ} \mathrm{C}$.

Table 1. Chemical composition of the tube

\begin{tabular}{|c|c|c|c|c|c|c|c|c|}
\hline \multirow{2}{*}{ Tested and standard tube } & \multicolumn{9}{|c|}{ Element content (\%) } \\
\cline { 2 - 9 } & $\mathrm{C}$ & $\mathrm{Mn}$ & $\mathrm{P}$ & $\mathrm{S}$ & $\mathrm{Si}$ & $\mathrm{Cr}$ & Mo & Fe \\
\hline Tube code 6 & 0.15 & 0.4 & 0.02 & 0.005 & 0.29 & 8.69 & 0.96 & Balance \\
\hline Tube code 7 & 0.12 & 0.48 & 0.02 & 0.004 & 0.39 & 8.89 & 1.00 & Balance \\
\hline \multirow{2}{*}{ Standard tube SA 213 T91 } & $0.07-$ & $0.30-$ & 0.02 & 0.01 & $0.20-$ & $8.00-$ & $0.85-$ & \multirow{2}{*}{ Balance } \\
& 0.14 & 0.60 & $(\max )$ & $(\max )$ & 0.50 & 9.50 & 1.05 & \\
\hline
\end{tabular}

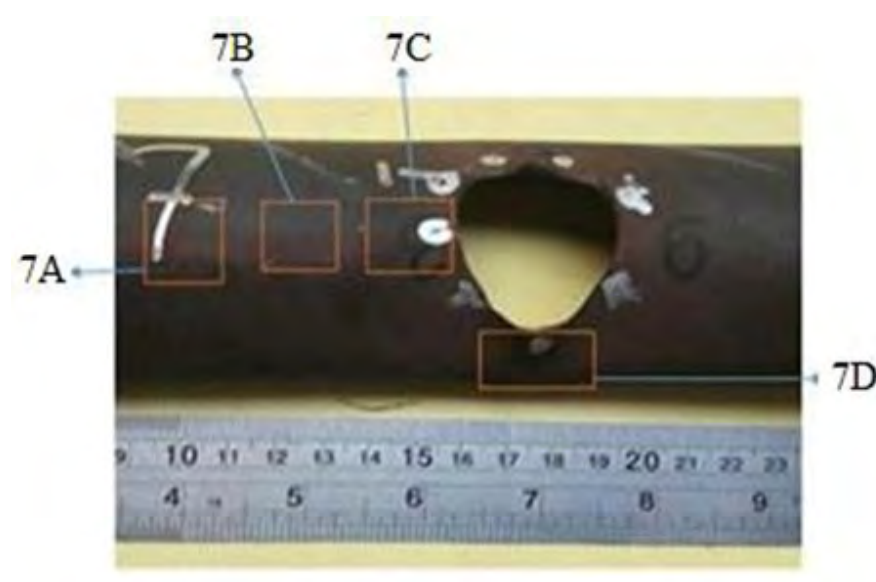

Figure 4. Sample location for hardness test and microstructure analysis of tube code 6

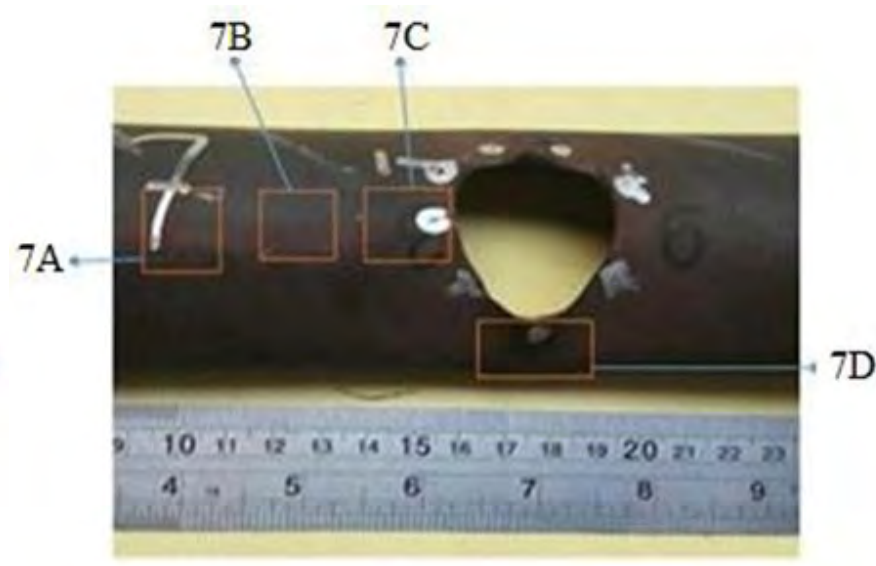

Figure 5. Sample location for hardness test and microstructure analysis of tube code 7 
Table 2. Hardness test and an estimated temperature of failure tube code 6

\begin{tabular}{|l|l|l|l|l|}
\hline \multicolumn{1}{|c|}{ Location } & \multicolumn{1}{c|}{$6 \mathrm{~A}$} & \multicolumn{1}{c|}{$6 \mathrm{~B}$} & \multicolumn{1}{c|}{$6 \mathrm{C}$} & $6 \mathrm{D}$ \\
\hline Hardness (HV) & 179.54 & 162.75 & 164.16 & 171.37 \\
\hline Operating temperatures $\left({ }^{\circ} \mathrm{C}\right)$ & 790 & 813 & 811 & 801 \\
\hline
\end{tabular}

Table 3. Hardness test and an estimated temperature of failure tube code 7

\begin{tabular}{|l|l|l|l|l|}
\hline \multicolumn{1}{|c|}{ Location } & \multicolumn{1}{c|}{$7 \mathrm{~A}$} & \multicolumn{1}{c|}{$7 \mathrm{~B}$} & \multicolumn{1}{c|}{$7 \mathrm{C}$} & \multicolumn{1}{c|}{$7 \mathrm{D}$} \\
\hline Hardness (HV) & 193.7 & 191.07 & 175.74 & 155.5 \\
\hline Operating temperatures $\left({ }^{\circ} \mathrm{C}\right)$ & 770 & 773 & 795 & 823 \\
\hline
\end{tabular}

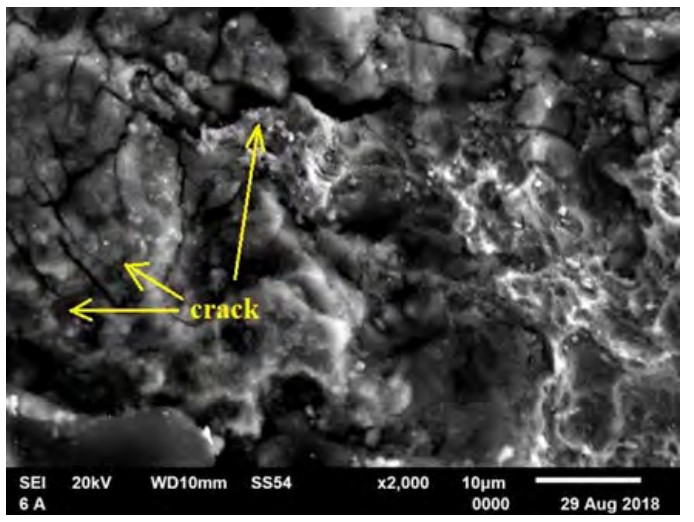

(a) Location at 6A-1

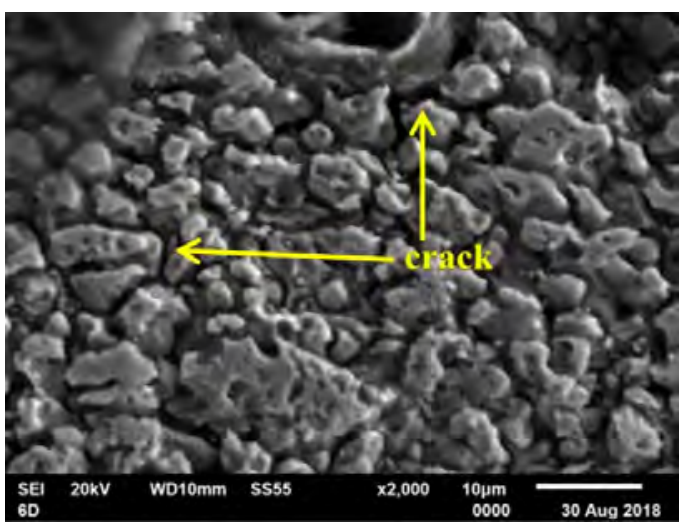

(c) Location at $6 \mathrm{D}-1$

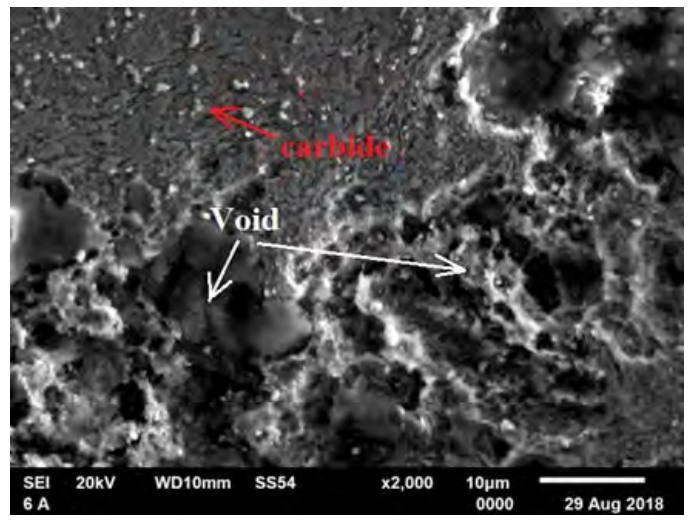

(b) Location at 6A-2

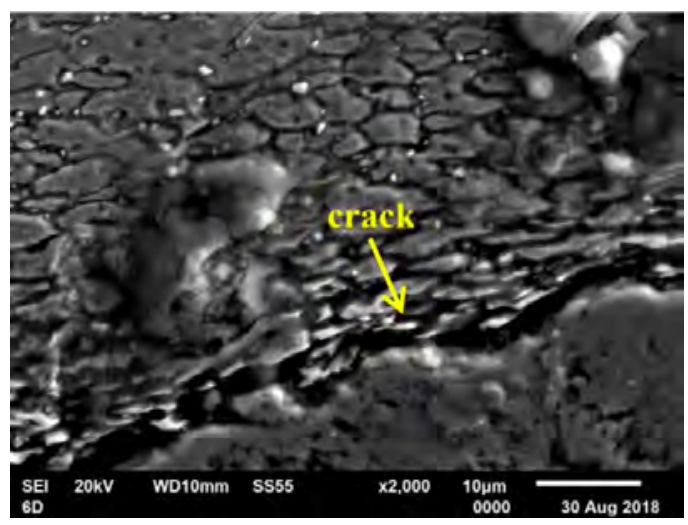

(d) Location at 6D-2

Figure 6. Microstructure of SEM tube code 6

\subsection{Microstructure analysis}

Sample location for analysis of microstructure tube with tube code 6 taken from the part as shown in Figure 4. Observations were carried out under the electron microscope (SEM). Observations in sample tube code 6 were made at location 6A, which was a bit far from the damaged area, and location 6D (which was a broken area). Figure $6 \mathrm{a}$ and $6 \mathrm{~b}$ shows the presence of grain boundary (intergranular crack) and creep voids. The extreme conditions of the grain boundary cracking are shown in Figure $6 \mathrm{c}$ and $6 \mathrm{~d}$, which are damaged areas.

Sample location for analysis of microstructure tube with code 7 taken from the part as shown in Figure 5 ,
Figure $7 \mathrm{a}$ to $7 \mathrm{f}$ shows the results of microstructural observations using SEM at locations 7A, 7C, and 7D. The micro-structures on the samples of 7C and 7D (Figure 7d and 7f) shows of rounding/spheroidization of M23C6 (indicated with a yellow arrow). Figure7 also shows the void (Figure 7a) formed along the grain boundary and form a crack (Figure 7c, showed with a white arrow). The rupture area (samples of 7C and 7D) shows void as it relates to one another (interconnected voids) occurring during operation. The void is a sign of creep damage that grows/develops at high temperatures. Local temperature increases above the allowable temperature limit caused by grain boundary sliding. The shift results in a decohe- 


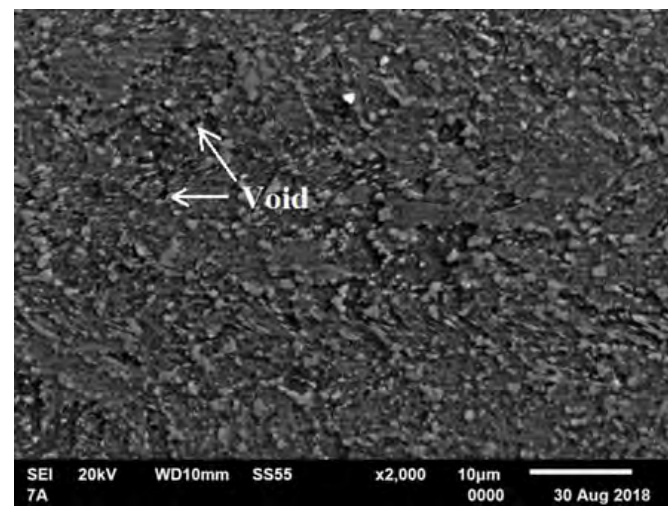

(a) Location at 7A-1

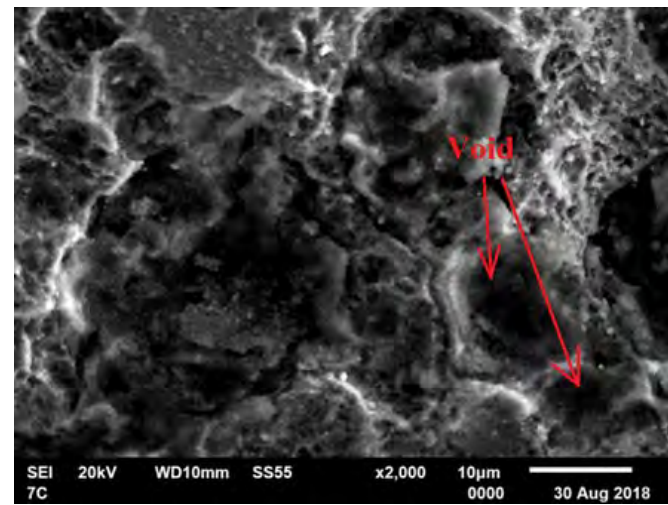

(c) Location at 7C-1

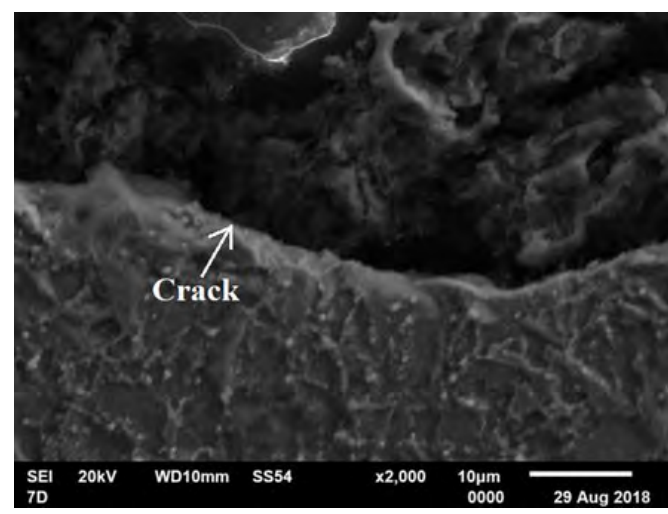

(e) Location at 7D-1

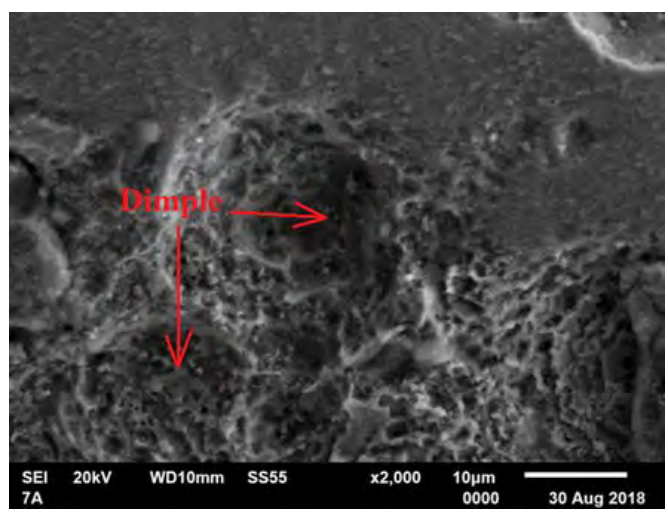

(b) Location at 7A-2

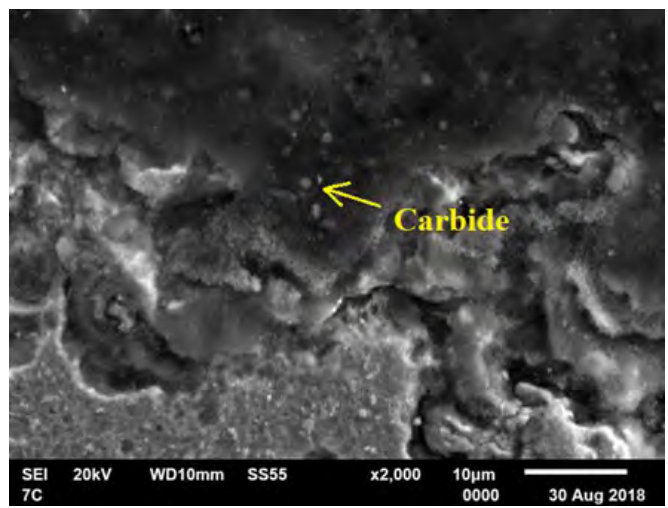

(d) Location at 7C-2

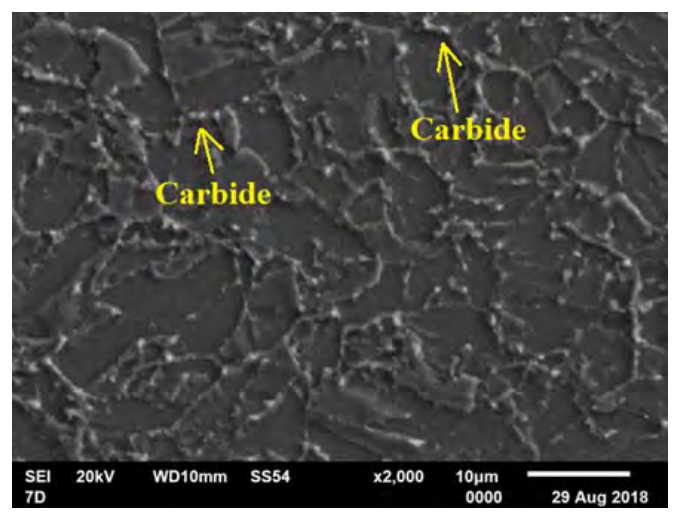

(f) Location at 7D-2

Figure 7. Microstructure of SEM tube code 7

sion/void of grain. In line with time, voids grow and become joined to each other. This results in a decrease in grain boundary strength and a decrease in the component ability to accept loads. Then the temperature increase in the tube wall affects the rounding of the carbide, voids [3], and softening of the material marked by hardness level reductions. This phenomenon will reduce the strength of the material and result in a flexible/soft fracture which is indicated by the rupture of the dimple (Figure $7 \mathrm{~b}$ and $7 \mathrm{c}$. red arrows).

To prove the presence of oxide layer or corrosion and compound alkali-sulfate complex, conducted microstructure analysis using SEM-EDS and the identification of slag taken from the tube surface using XRD or X-Ray Diffraction, technique commonly used for identification of crystalline materials and analysis of unit cell dimensions.

The result of the qualitative analysis of SEM-EDS in Figure 8, shows the corrosive elements of Si and Ca. The presence of such elements indicates that a corrosion attack is caused by a mixture of ash particles which mostly composed are iron oxides and hydroxides elements. The result of SEM-EDS in Figure 8 also detects the existence of elements $\mathrm{Al}, \mathrm{Fe}, \mathrm{Ti}$, and $\mathrm{V}$. The material content in coal is very diverse, such as moisture, volatile matter which is an active substance found in coal, consisting of flammable gases such as: methane $\left(\mathrm{CH}_{4}\right)$, hydrogen $\left(\mathrm{H}_{2}\right)$, carbon 
monoxide (CO), and non-combustible substances such as: water vapor $\left(\mathrm{H}_{2} \mathrm{O}\right)$, carbon dioxide $\left(\mathrm{CO}_{2}\right)$. Fixed carbon and ash content is the final result after burning the coal and the inherent values of moisture, volatile matter and fixed carbon are obtained. The presence of these elements in coal ash can be caused by incomplete combustion process [2] or the elements already contained in the coal used.

The presence of $\mathrm{CaSO}_{4}$ is shown by the results of the
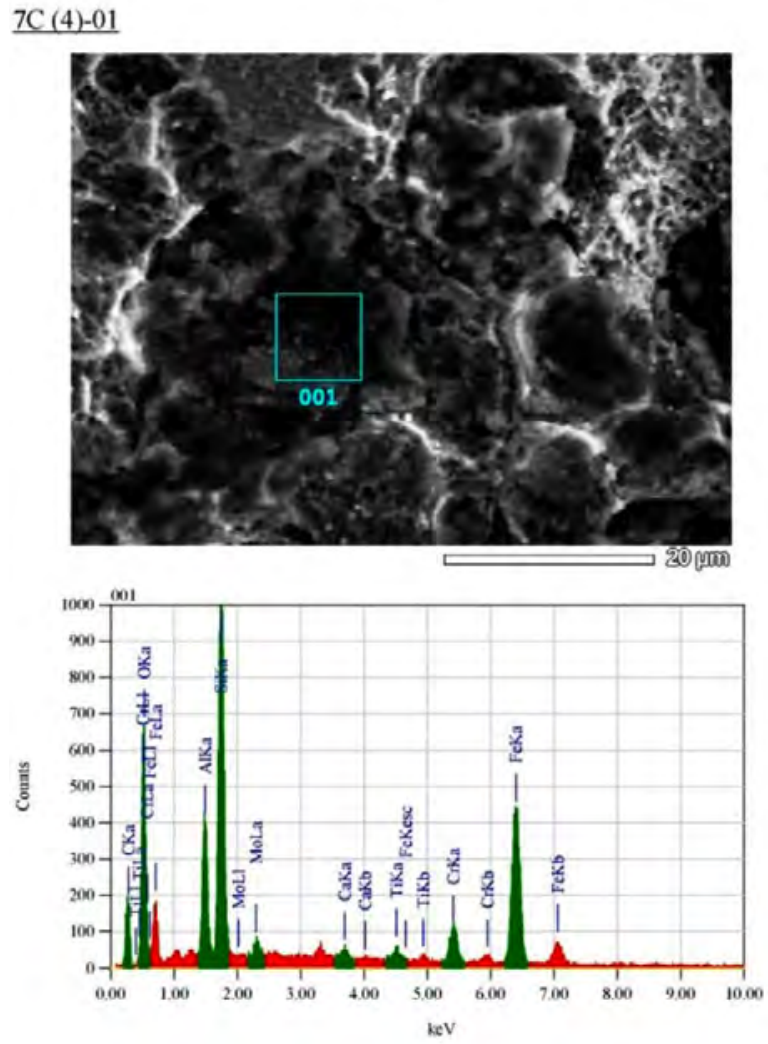

(a) Location 7C
X-ray diffraction test against the scale taken from the tube surface, as shown in Figure 9 .

The presence of $\mathrm{CaSO}_{4}$ is shown by the results of the $\mathrm{X}$-ray diffraction test against the scale taken from the tube surface,as shown in Figure 9a. The results of XRD analysis on the deposit scale/slag shown in Figure $9 \mathrm{~b}$ prove the deposits of slag also have corrosion products in the form of iron oxides and hydroxides.

\section{$\underline{7 D(4)-01}$}
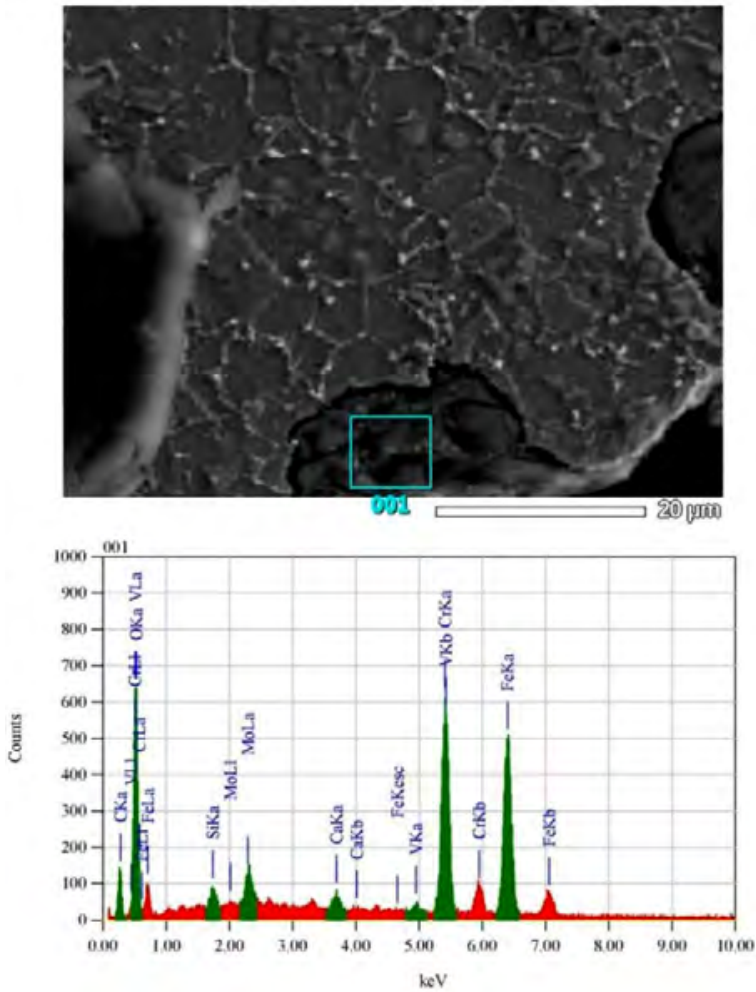

(b) Location 7D

Figure 8. The result of qualitative analysis of SEM-EDS tube code 7

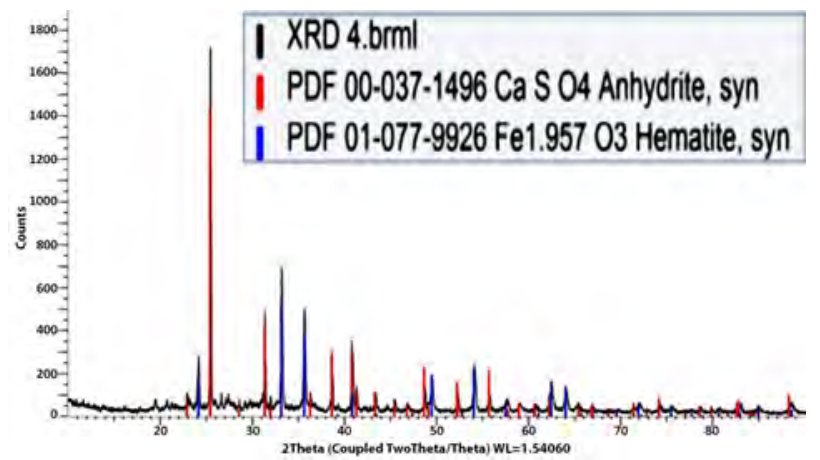

(a) The presence of $\mathrm{CaSO}_{4}$

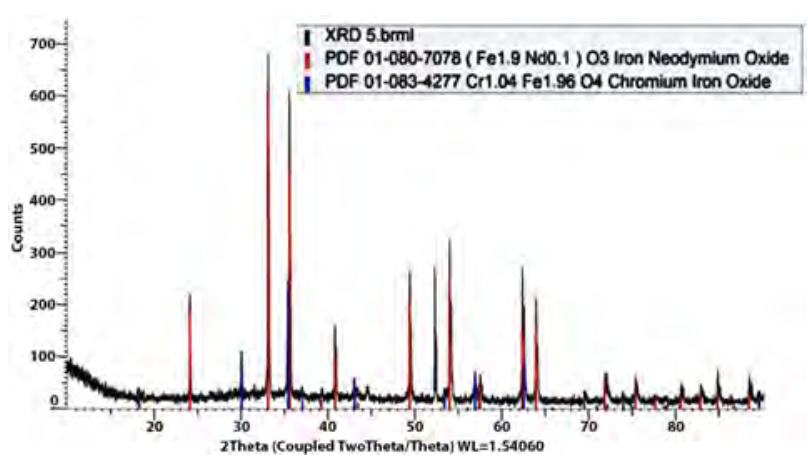

(b) The presence of iron oxides and hydroxides

Figure 9. Spectrum characteristics X-ray deposit 


\section{Discussion}

The superheater tube, when in operation, is bypassed by water which is then heated with fire from burning coal. During the tube operates and exposed at high temperatures (equivalent to $43 \%$ of the steel temperature), voids meet one another and occur a creep voids magnification, which causes cracks along the grain or intergranular boundary crack [10]. Tube code 6 shown an intergranular crack begins with void formation at the grain boundary and gradually voids more and more and meets with the other voids. This tube is thought to operate beyond the temperature limit of heat-resistance so that the tube is deformed. It is indicated by the occurrence of swelling. The heat fluctuation of tube making tube is experiencing stretched out when exposed to heat and shrinking when the heat is reduced or lost [10].

In tube code 7 , the type of rupture is thin lip fish mouth. The tube is seen experiencing wall thinning on damaged areas, and the tube undergoes plastic deformation. Damage to the thin lip type tube where there is thinning starting from the outer wall of the tube and there is a corrosion product which indicates the damage mechanism that occurs is erosion and corrosion. It is shown from the thickness measurement where localized thinning occurs in the rupture area. Thickness measurements show that thickness reduction occurs ununiformly. In the thin lip rupture area, the tube significantly decreased wall thickness. The inconsistency of wall thickness occurs on one side. The operating temperature received by the tube during the failure can be predicted based on hardness testing results.

Analysis of the test results showed that the damage to the tube superheater due to the tube was exposed at a higher temperature than the specified operating temperature. This, among other things, is evidenced by the discoloration around the fish mouth opening area which signifies the interaction of the tube with a high-temperature flame.

In normal operation, the coal was burned, causing a fire to arise, which heated a tube filled with water so that it becomes steam. The coal fire produces ash that sticks to the tube. In over a period of time, more and more of the sticky ash in the outer wall of the tube becomes a slag that is difficult to clean. Some part of the tube is free from slag ash or oxide layer and deposit. This slag ash deposit results in uneven internal heating circulation within the tube. Deposit slagging resulted in the lid of the gas route around the tube. Creating the flow of flue gas will switch to the freer surrounding tube area. The tube area which is not enclosed by slag or clean area of the tube, has a higher flow speed. Erosion of the outer wall and occurs thinning of the tube wall in a clean area of the tube. It reduces the heat efficiency of metal tubes and causing some parts of the tubes to over temperature. This resulted in increased tension and eventually exceeded the tube material strength betas.

The same failure mechanisms that occur at tube code 7 are erosion due to uneven steam flow in and corro- sion that occur at the same time, and occur rapid/shortterm overheating. Nevertheless, the mechanism of failure is more dominated by flue gas erosion and followed rapid/short-term overheating because of deposit slagging on the outer wall of the tube. This is because the thinning that occurs starts from the outside, and the resulting corrosion products are insignificant.

\section{Conclusion}

The damage that occurs on the tube code 6 and 7 were thick lip rupture and thin lip fish mouth rupture, respectively. In tube code 6 , thick lip rupture is caused by the creep mechanism where the tube is exposed at high temperatures (exceeding the operating temperature limit) for a long time. Meanwhile, in tube code 7, thin lip fish mouth rupture is caused by erosion due to uneven steam flow in and fly/coal ash corrosion, which tube is exposed at high temperatures (exceeding operating temperature limit) in a short time. Overheating and flue gas erosion occurs caused by deposit slagging on the outer wall of the tube. The failure of tube superheater can be avoided by the removal of scale or deposits accumulating on tubes. Scale or deposits can be removed using the existing soot blower in the boiler and can be prevented by using fuels that have a low value of slagging and fouling indexes.

\section{References}

[1] R. Clapp, Modern Power Station Practice: Boilers and Ancillary Plant. Boilers and Ancillary Plant, Pergamon Press, 1991.

[2] A. Movahedi-Rad, S. Plasseyed, and M. Attarian, "Failure analysis of superheater tube," Engineering Failure Analysis, vol. 48, pp. 94-104, 2015.

[3] G. K. Gupta and S. Chattopadhyaya, "Critical failure analysis of superheater tubes of coal-based boiler.," Strojniski Vestnik/Journal of Mechanical Engineering, vol. 63, no. 5, 2017.

[4] D. Jones, "Creep failures of overheated boiler, superheater and reformer tubes," Engineering failure analysis, vol. 11, no. 6, pp. 873-893, 2004.

[5] A. Husain and K. Habib, "Investigation of tubing failure of super-heater boiler from kuwait desalination electrical power plant," Desalination, vol. 183, no. 1-3, pp. 203-208, 2005.

[6] B. Haghighat-Shishavan, H. Firouzi-Nerbin, M. Nazarian-Samani, P. Ashtari, and F. Nasirpouri, "Failure analysis of a superheater tube ruptured in a power plant boiler: Main causes and preventive strategies," Engineering Failure Analysis, vol. 98, pp. 131-140, 2019.

[7] Z. Baoyou, L. Zhonghong, C. Yuexian, and F. Xigang, "Analysis of a boiler pipe rupture," Engineering Failure Analysis, vol. 13, no. 1, pp. 75-79, 2006. 
[8] M. Rahman, J. Purbolaksono, and J. Ahmad, "Root cause failure analysis of a division wall superheater tube of a coal-fired power station," Engineering Failure Analysis, vol. 17, no. 6, pp. 1490-1494, 2010.

[9] J. Ahmad, J. Purbolaksono, L. Beng, and A. Ahmad, "Failure evaluation on a high-strength alloy sa213-t91 super heater tube of a power generation," Proceedings of the Institution of Mechanical Engineers, Part E: Journal of Process Mechanical Engineering, vol. 224, no. 4, pp. 269-273, 2010.
[10] P. Psyllaki, G. Pantazopoulos, and H. Lefakis, "Metallurgical evaluation of creep-failed superheater tubes," Engineering Failure Analysis, vol. 16, no. 5, pp. 14201431, 2009.

[11] D. Ghosh, S. Ray, A. Mandal, and H. Roy, "Failure investigation of radiant platen superheater tube of thermal power plant boiler," High Temperature Materials and Processes, vol. 34, no. 2, pp. 171-175, 2015. 